\title{
O LIVREIRO QUE PREFACIAVA (E OS LIVROS ROUBADOS); OS PREFÁCIOS DE FRANCISCO ROLLAND E A CIRCULAÇÃO DE LIVROS NO IMPÉRIO PORTUGUÊS AO FIM DO SÉCULO XVIII ${ }^{1}$
}

\author{
The bookseller who wrote prefaces (and the stolen \\ books); the prefaces of Francisco Rolland and book \\ circulation in the Portuguese Empire at the end of the \\ 18th Century
}

\author{
Claudio DeNipoti*
}

\begin{abstract}
RESUMO
Este artigo percorre os escritos do livreiro e impressor francês radicado em Lisboa, Francisco Rolland, que escrevia paratextos para suas edições, na forma de prefácio, avisos ao leitor e notícias, nas quais elabora padrões discursivos relativos às questões fundamentais do mercado de livros português do fim do século XVIII: a utilidade, a necessidade, a instrução e o serviço ao império. Simultaneamente, Rolland era um comerciante hábil e perceptivo, que sabia circular entre os letrados portugueses, buscando antecipar gostos e demandas livreiras, ao mesmo tempo que se via às voltas com os mecanismos de censura para publicar e circular seus livros. Este estudo tenta compreender a atuação deste agente do livro, no contexto mais complexo da ilustração lusitana.
\end{abstract}

Palavras chave: Francisco Rolland, História do Livro, Império Português, Real Mesa Censória

\footnotetext{
ABSTRACT

This article browses the writings of French bookseller and printer stablished in Lisbon, Francisco Rolland, who wrote paratexts in

1 Pesquisa realizada com recursos da CAPES e CNPq.

* Doutor em História (1998) pela Universidade Federal do Paraná. Professor associado da Universidade Estadual de Ponta Grossa e bolsista produtividade da Fundação Araucária.
} 
his editions, such as prefaces, introductions, warnings to the reader and newsletters, in which he makes discursive patterns relating to the fundamental questions around the Portuguese book trade in the $18^{\text {th }}$ Century: utility, need, instruction, and service to the Empire. At the same time, Rolland was an apt merchant, who knew how to foresee the changes in taste and the demands of the book trade, while dealing with the censorship machinery in order to publish and market his books. This work tries to understand how this agent of the book acted in the wider context of the Portuguese Enlightenment.

Keywords: Francisco Rolland, Book History, Portuguese Empire; portuguese censorship

Corria o ano de 1779 quando um francês residente em Lisboa terminava a coleção de provérbios que pretendia publicar, escrevendo um longo prólogo que sumarizava suas atividades no mercado editorial português. ${ }^{2}$ Escritor habitual de paratextos nas obras que editava, seus prólogos, advertências, avisos, discursos e prefações acompanharam grande parte dos livros publicados em sua empresa, a Typografia Rollandiana, ao longo das três últimas décadas do século XVIII e na primeira década do século XIX.

Como em todos os seus paratextos, este foi bastante enfático sobre a importância dos livros em geral e daquele livro em particular, ao mesmo tempo que não media esforços para criar uma imagem de cooperação e integração completa do editor/livreiro com o Antigo Regime português e suas estruturas de poder. O prefaciador era Francisco Rolland, impressor e livreiro, com loja, até 1790, no Largo de Nossa Senhora do Loreto, e depois desta data, na Rua Nova dos Mártires, número 15, em Lisboa. ${ }^{3}$

Neste prólogo, Francisco Rolland, escondendo-se timidamente no acrônimo F.R.I.L.E.L. (Francisco Rolland, Impressor e Livreiro em Lisboa), ${ }^{4}$ informava, antes de mais nada, ao leitor sua raison d'être: fazer livros "puros, e desabusados" para que o Estado

2 ROLLAND, Francisco. ADÁGIOS, Provérbios, Rifãos e anexins da língua portuguesza; tirados dos melhores Authores Nacionaes e recopilados por ordem Alfabetica. Lisboa: na Typografia Rollandiana, 1780.

3 CURTO, Diogo Ramada, et al. As gentes do livro. Lisboa, século XVIII. Lisboa: Biblioteca Nacional, 2007, p. 100.

4 ANDRADE, Adriano da Guerra. Dicionário de pseudónimos e iniciais de escritores portugueses. Lisboa: Biblioteca Nacional Portugal, 1999, p. 96. 
cumprisse sua necessidade indispensável de obter a "verdadeira instrucção". "Vindo da França, da região próxima à Suíça de onde se originou a maioria dos livreiros franceses em Portugal na segunda metade do século XVIII, ${ }^{6}$ Rolland chegou em Lisboa em 1765, aos 22 anos. Originalmente sócio da empresa Borel \& Rolland, reforçando a tendência do grupo de imigrantes franceses de estabelecerem "formas associativas de gerência [que] permitem que os sócios se especializem", ${ }^{7}$ Rolland desfez esta sociedade para abrir sua própria casa comercial por volta de 1771, quando foi descrito, na documentação comercial portuguesa, como "comerciante de nasção francesa e morador na rua direita do Loureto", casou-se em 18 de junho de 1775 com Maria Catarina Van Bockstael. ${ }^{8}$

Ao iniciar os negócios tipográficos, Rolland inverteu parcialmente a lógica da trajetória de seus conterrâneos - Bertrand, Borel, e outros - que se dedicaram quase exclusivamente ao comércio de livros, ao passo que ele enfatizou a impressão em suas atividades comerciais. Isto é compreensível à luz da importância (e rentabilidade financeira) que a impressão adquirira àquela época, em que o livro era percebido como produto comercial e como bem cultural, simultaneamente. $\mathrm{O}$ negócio tipográfico significava também um empreendimento mais estável, dada "a natureza técnica da atividade [e] a demorada e difícil aprendizagem das artes gráficas". 9

Desta forma, e investindo sistemática e constantemente na reedição de obras clássicas portuguesas, e na tradução de obras clássicas francesas e inglesas, frequentemente reeditadas ao longo das quatro décadas em que esteve à frente da Rollandiana, Francisco foi provavelmente um dos primeiros editores de Portugal - na acepção que o termo assume ao longo do século XIX, como alguém que atua para além da indicação do seu nome na folha de rosto, agindo

5 ROLLAND, op. cit. p. 4.

6 GUEDES, Fernando. O livro e a leitura em Portugal; subsídios para a sua história séculos XVIII e XIX. Lisboa: Verbo, 1987, p. 15, ss; GUEDES, Fernando. Livreiros Franceses em Portugal no Seculo XVIII. Lisboa: Academia Portuguesa da História. 1998.

7 CAEIRO, Francisco da Gama. Livros e livreiros franceses em Lisboa, nos fins de setecentos e no primeiro quartel do século XIX. Boletim da Biblioteca da Universidade de Coimbra, vol. 35, 1980, p. 139-168.

8 CURTO, op. cit. p. $483 ; 499$.

9 CAEIRO, op. cit. p. 149. 
diretamente nos processos criativos. ${ }^{10} \mathrm{O}$ prefácio dos Adágios também apresenta uma inversão, na qual o impressor/editor se torna autor:

\begin{abstract}
Digno de nota é o facto de o tipógrafo ter assumido a iniciativa de elaborar ele próprio a colectânea dos textos proverbiais. Francisco Rolland acede ao estatuto de autor, e de autor em língua portuguesa. Esse estatuto, discretamente consignado pela abreviatura F.R.I.L.E.I., era uma iniciativa prestigiante, já então partilhada por outros raros impressores, seus contemporâneos, como Francisco Luis Ameno. ${ }^{11}$
\end{abstract}

A autoria da obra aponta para "aspectos importantes da personalidade e actuação culturais" de Francisco Rolland, que eram "o seu gosto pelas edições apuradas", particularmente de obras clássicas; "o interesse pelas tradições populares" e seu empenho por reedições e traduções de obras literárias. ${ }^{12} \mathrm{O}$ prefácio continuava, reafirmando as ideias de Rolland sobre o universo dos livros, como fundamento "solido, e puro das Sciencias", reforçando noções de pátria vinculadas à monarquia absoluta ilustrada, já que "os Monarcas mais illuminados da Europa culta, e civilizada tem dado franca passagem áquelles bons Livros, que nos patenteaõ a primitiva Antiguidade, ou das Sciencias, ou dos Factos Historicos Seculares, ou Ecclesiasticos". O livros "sãos" levam os homens a serem "bons Christãos, e Sabios". Vale ressaltar que isto acontecia dentro do amplo processo de ilustração portuguesa, caracterizada, em diversos momentos, como utilitarista, e definida como um "triunfo esmagador do empirismo britânico numa extensão inigualada em qualquer outro

10 CHARTIER, Roger. A ordem dos livros; leitores, autores e bibliotecas na Europa entre os séculos XIV e XVIII. Brasília: Editora UNB, 1998, p.47.

11 BAGÃO, Maria Teresa Sousa. Adagios, proverbios, rifãos e anexins, de Francisco Rolland: edição e estudo. Dissertação, Mestrado em Estudos Portugueses. Universidade de Aveiro, Aveiro, 2006, p. 20.

12 CAEIRO, op. cit. p. 155. 
lugar" ${ }^{13}$, uma vez que o empirismo foi, de fato, a ferramenta utilizada para superar a dominação escolástica.

Esta é a razão, alegada por Rolland, de sua atuação: ser útil a Portugal, levando às pessoas conhecimentos que permitam a educação dos portugueses tanto pela via escolar quanto em seus lares e círculos socioculturais. Por isso ele tinha "tido o animo de reimprimir Obras antigas; imprimir outras de novo, mandar traduzir outras" que auxiliassem os homens a reformar "seus corruptos costumes, ou das suas mal vigorizadas Sciencias". Segundo ele, sua tipografia visava sanar uma deficiência no mercado editorial português, que podia ser visualizada em outras partes:

As Sciencias profanas enfermão do mesmo mal. A falta de Livros, onde as Sciencias, ou Artes estejão tratadas methodica e encantadoramente, cria ou pedantes, ou ignorantes. Soterraõ-se as antigas Composições; esquecese de ataviar, e tecer outras de novo. Não se traduzem na Lingua vulgar aquelles livros, dos quaes os Homens tirem cochecimentos [sic.] precisos, para pulirem os talentos, utilizarem os outros Homens, e formarem os Cidadãos zelosos, e amantes da Patria; e juntamente dispertar briosos ciumes de Humanidade, de Religião e de utilidade. Perder-se muitas vezes o amor ás Artes liberaes, ás Manufacturas, ao Commercio, e á Agricultura por não andarem nas mãos de todos, ou Livros originaes, ou Traduç̧ões, onde gostem, e se enamorem os Homens da sua utilidade e necessidade.

Neste prefácio, Rolland se dizia agradecido pela acolhida recebida na nova pátria, indicada principalmente pela aceitação de seu trabalho editorial pelos leitores e compradores de livros na capital lusitana. Isto o levou a acreditar também na boa recepção de sua própria obra - uma compilação de provérbios tirados em grande parte

13 ISRAEL, J. I. The intellectual drama in Spain and Portugal. In: Radical Enlightenment: philosophy and the making of modernity. 1650-1750. Oxford: Oxford University Press, 2001, p.528-540. 
do dicionário de Bluteau ${ }^{14}$ - pois Portugal reunia aquilo que ele considerava reiteradamente em seus textos, como as condições ideais para o comércio de livros, pois em Portugal, "o corpo dos Sabios, que conduz as Sciencias, estão cheios daquella illuminação, e talentos, com que desejão que os mais as tenhaõ".

Esta é a tônica dos seus diversos avisos, prólogos, advertências e prefácios do editor, bem como de suas (raras) dedicatórias. Foram cerca de trinta paratextos, publicados entre 1770 e 1800, introduzindo os diversos empreendimentos editoriais de Rolland. Estes foram relacionados à reedição de obras de escritores portugueses, como a reedição de 1781 das Obras poeticas de Domingos dos Reis Quita, que o próprio Rolland publicara originalmente em 1766, em sua associação com José Agostinho Borel ${ }^{15}$ ou ainda a reedição das Reflexoens sobre a vaidade dos homens de Mathias Aires Ramos da Silva de Eça, cuja edição original foi feita em 1752 por Luis Ameno, e que Rolland relançou, em terceira e quarta edições em 1778 e 1781 respectivamente (a segunda edição tendo sido feita por Antonio Vicente da Silva em 1761). ${ }^{16}$ Ele também prefaciou diversas traduções que publicou, como aquela que Francisco Pujol de Padrell fez do primeiro volume da Medicina domestica de Willian Bucham em 1788, ou da Noticia da mythologia de Francisco Xavier Rigord, que Rolland publicou em $1780 .{ }^{17}$ Porém, ele só assumiu a autoria dos Adágios e da tradução, que ele mesmo imprimiu em 1782, da Peregrinação de um christão ou viagem para a cidade $^{\text {celeste }^{18}}$ de John Bunyan (que não é citado pelo tradutor/impressor). Em todos os outros livros, mesmo quando há a

14 BLUTEAU, D. Raphael. Dicionário Vocabulário Portuguez e Latino. Coimbra: Colégio de Artes da Companhia de Jesus, 1712.

15 MICENIO, Alcino. Obras poeticas de Domingos dos Reis Quita... Lisboa: Borel \& Rolland, 1766; MICENIO, Alcino. Obras poeticas de Domingos dos Reis Quita.... Nova edição com um prólogo do editor. Lisboa: Na Typografia Rollandiana, 1781.

16 RAMOS, Mathias Aires. Reflexoens sobre a vaidade dos homens. Lisboa: Typografia Rollandiana, 1778. 3a edição.

17 BUCHAN, Guilerme. Medicina domestica ou tratado completo dos meios de conservar a saúde. Lisboa: Na Typographia Rollandiana, 1788. [Trad. Francisco Pujol de Padrell]; RIGORD, Francisco Xavier. Noticia da mythologia; onde se contem em fórma de dialogo a historia do paganismo, para a inteligencia dos antigos poetas. Lisboa: na Typografia Rollandiana, 1780. [trad. de A. J. T.].

18 BUNYAN, John. Peregrinação de um christão ou viagem para a cidade celeste. Lisboa: Na Typographia Rollandiana, 1782. [Trad. F.R.I.L.E.L.]. 
ausência de referências aos autores, Rolland assinou somente os prefácios, sempre como "editor". Cumpre esclarecer que estes cerca de trinta paratextos acompanham uma pequena parcela dos livros efetivamente impressos por Francisco Rolland, o que pode ser verificado em um estudo quantitativo da sua profícua atividade editorial. Porém, eles são suficientes para buscarmos algumas pistas sobre o funcionamento do comércio de livros e o papel deste livreiro na sociabilidade letrada portuguesa do século XVIII.

É bom apontarmos também que Rolland abria mão de diversas estratégias comerciais comuns aos livreiros e impressores europeus, que indicavam seu bom conhecimento do mercado de livros. Além de recursos herdados do passado da história do comércio de livros, ele utilizou novidades como os anúncios na Gazeta de Lisboa "que se torna[ram] um veículo normal, cada vez mais difundido[s], de comunicação com o público", ${ }^{19}$ como foi o anúncio sobre o lançamento da tradução portuguesa do D. Quixote:

Sahio a luz o Engenhoso Fidalgo D. Quixote de la Mancha, por Miguel de Cervantes Saavedra, traduzido em português, em 8.o, 6. vols. Vende-se por 2880 reis em casa de Francisco Rolland, no largo e nas casas novas de N. Senhora do Loreto. Esta obra, vertida em todas as línguas das nações cultas da Europa, de justiça aparece agora na nossa, para recreio e instrução dos Portugueses: ela é a primeira entre todos os Romances Cômicos, já pelo gosto, simplicidade e graça, já pela pureza e natural do estilo, já pela verdade dos retratos, já pela arte de narrar e misturar as aventuras sem nada estragar, e já, sobretudo, pelo talento de instruir divertindo; achando-se a cada página cómicos quadros, judiciosas reflexões, e tanta arte que todos os Sábios lhe tributam o merecimento da originalidade. ${ }^{20}$

19 CAEIRO, op, cit. p. 163.

20 ALMEIDA, Manuel Lopes de. Notícias históricas de Portugal e Brasil (1751-1800). Coimbra: Coimbra Editôra Ltda. 1964, p. 285-6. 
De modo similar, os catálogos dos livros à venda - gênero de divulgação comercial que ganhou destaque no cenário editorial português na segunda metade do século XVIII, ${ }^{21}$ e no qual ele foi um dos pioneiros em Lisboa $^{22}$-, sempre traziam os títulos que desde a década de 1770, oferecia para venda e leitura, entre importações diretas dos países de edição (principalmente entre esta data e a década de 1780) e impressões próprias, mais frequentes nos catálogos do início do século XIX, como os 160 títulos listados no Catalogo dos livros impressos á custa de Francisco Rolland, de $1812,{ }^{23}$ ou os 149 listados na edição de 1814 do mesmo catálogo. Sua carreira como comerciante de livros - como a de diversos outros livreiros do período, que compartilhavam a origem francesa - foi permeada por uma série de eventos e processos (como a impressão de catálogos) em que ficam manifestas as estratégias de comércio utilizadas por eles. Em seus catálogos da década de 1770, Francisco Rolland incluiu "Avisos ao público" que deixavam claras as intenções da publicação do catálogo: "Quem quizer alguns livros do dito catalogo, poderá com toda a brevidade alcançallos, escrevendo ao dito Contratador de Livros. ${ }^{24}$ Publicando diversos suplementos ao catálogo ao longo da década (ainda que não semestralmente, como desejava) Rolland ampliou a explicação de seu modo de negociar:

\begin{abstract}
AVISO AO PUBLICO
O mesmo Francisco Rolland não duvida trocar os seus livros por outros de qualquer qualidade que sejaõ ou por outro qualquer genero de fazenda; e tambem se encarrega de apromptar as encomendas de livros, que se lhe fizerem, ou seja para o Reino, ou para fóra delle; advertindo que as pessoas que lhas fizerem por cartas, terão a bondade de notar o lugar das impressoens, e a data dos annos, como se achão no presente Catalogo. De
\end{abstract}

21 GUEDES, Fernando. O livro e a leitura ... p. 82-96.

22 CAEIRO, op. cit., p. 149.

23 CATALOGO dos livros impressos á custa de Francisco Rolland, impressor, Livreiro em lisboa, e que se achaõ a venda no seu armazem, na Rua Nova dos Martires, numero 15, com seus justos preços, encadernados. Lisboa: Na Typografia Rollandiana, 1812.

24 ROLLAND, Francisco. Suplementum Ad Catalogum Librorum Omnium Facultatum, \& variis linguis qui venales prostant apud Franciscum Rolland. Lisboa: na Officina Patriarcal, 1773. 
tempo em tempo se publicará hum supplemento a este Catalogo, para que as pessoas de letras tenhaõ noticia dos livros novos que chegarem de fóra. $[\ldots]^{25}$

Entre suas estratégias editoriais, Rolland recorria às respostas dos leitores, que serviram para definir publicações de popularização, como o anuário (com sete volumes) Miscellanea Curiosa $e$ Proveitosa... ${ }^{26}$ De fato, ainda que o primeiro volume, de 1779, contenha o Prefácio do Editor, os volumes 3 e 4 (1781 e 1782, respectivamente) trazem, como prefácios, longas cartas de leitores (Marcos José de Barros, de Braga no volume 3 e J. A. de V. M. e M. de Coimbra, no volume 4). Nestas, os leitores agradeceram a iniciativa, elogiando Rolland: "Na verdade teve v. m. boa idéa em ajuntar todas aquellas notícias, para muitos novas, e para todos necessarias". ${ }^{27}$ Ao mesmo tempo, fizeram pedidos de inclusões e traduções específicas, e recomendaram percursos editoriais a serem seguidos, enquanto criticam o mercado editorial português por não conter mais obras semelhantes, já que "[n]ão há dúvida, que nós temos muitos Livros, em que nenhuma outra cousa se acha senaõ puerilidades, quimeras, e falsidades". ${ }^{28}$

Este conhecimento acumulado sobre o comércio de livros em Portugal foi adquirido tanto ao importar livros para Portugal (em particular, vindos da Suíça, nas vizinhanças de sua terra natal no Delfinado), quanto ao comercializar livros dentro do império, com especial ênfase no trato com as cidades brasileiras, ${ }^{29}$ e informou as escolhas editoriais de Francisco Rolland, que expressou com frequência em seus prefácios sua expectativa de como os livros

25 ROLLAND, Francisco. Suplementum Ad Catalogum Librorum Omnium Facultatum, \& variis linguis qui venales prostant apud Franciscum Rolland. Lisboa: na Officina Patriarcal, 1777.

26 ARAÚJO, Ana Cristina. A cultura das luzes em Portugal: temas e problemas. Lisboa: Livros Horizonte, 2003, p. 79.

27 BARROS, Marcos José de. CARTA ESCRITA ao EDITOR. In MISCELLANEA curiosa, e proveitoza ou compilação tirada das melhores obras das nações estrangeiras. Lisboa: $\mathrm{Na}$ Typografia Rollandiana, tomo III, 1781.

28 J. A. de V. M. e M. CARTA ao EDITOR Senhor Francisco Rolland. In MISCELLANEA curiosa, e proveitoza ou compilação tirada das melhores obras das nações estrangeiras. Lisboa: Na Typografia Rollandiana, tomo IV, 1782.

29 CAEIRO, op. cit, p. 164. 
seriam recebidos pelos leitores, ao mesmo tempo que reiterava sua disposição em acatar a participação desses mesmos leitores no processo de decisões editoriais. Na Miscellanea curiosa e proveitoza, ele esperava bom acolhimento "pois como não estamos obrigados ao publico com vinculo algum, que nos prenda, o recebimento que lhe fizerem nos servirá de regra, para nos regularmos, se havemos proseguir, ou abrir mão da empreza". ${ }^{30}$ Introduzindo o Naufragio $e$ lastimoso sucesso da perdição de Manoel de Sousa de Sepulveda, Rolland reiterava estas disposições:

Porém, se o Publico se dignar em attender a este nosso desvelo, talvez nas futuras edições e seguintes Tomos, se ajunte a cada hum dos Authores as suas vidas assim como se contém na sobredita Bibliotheca, bem que não recusaremos de ajuntar em Notas algumas novas descubertas, e noticias, que os Sabios tenhã̃ achado modernamente, e que não chegassem ao conhecimento do Sabio Barbosa, que nem por isso merece se desacredite. $^{31}$

Mais do que esperar um retorno financeiro adequado aos seus investimentos, Rolland esperava mesmo que os leitores interferissem e apontassem suas "faltas, e descuidos", avisando o editor "sinceramente delles para os emendarmos nas futuras edições". ${ }^{32}$ Ele estabelecia um diálogo constante com os leitores, construindo um discurso desejante (e normatizador) sobre as formas como os livros que publicava deviam ser recebidos Assim, o livro de poesias de Manoel da Veiga, Laura de Anfriso ${ }^{33}$ (cuja primeira edição fora feita em 1628) parecia ser objeto de boa recepção pelos leitores que não se desagradariam da reimpressão colocada a público. Ele se expressava

30 MISCELLANEA curiosa, e proveitoza ...,Tomo I.

31 REAL, Jeronimo Corte. Naufragio e lastimoso sucesso da perdição de Manoel de Sousa de Sepulveda... Lisboa: Na Typografia Rollandiana, 1783.

32 LIAO, Duarte Nuno. Origem e orthographia da língua portugueza. Lisboa: Na typographia Rollandiana, 1784.

33 VEIGA, Manoel. Laura de Anfriso; poesias. Lisboa: na Typografia Rollandiana, 1788. 
em termos semelhantes no prefácio às Obras poeticas de Domingos dos Reis Quita, dizendo crer "que o Público acolherá benignamente este meu desejo, e vontade, a qual ainda que pareça tem por mira a minha utilidade, com tudo he maior o gosto, que tenho de fazer mais conhecidos aquelles Authores, que o merecem, e de que se possa tirar utilidade. ${ }^{\prime 34}$ Estas expectativas diziam respeito às traduções, tanto quanto às reimpressões ou edições originais. Ao prefaciar a tradução que Antonio José Teixeira fez da Noticia da mythologia, Rolland se perguntava, retoricamente, se a tradução portuguesa teria um acolhimento igual àquele que os franceses deram à obra original, para responder: "Creio que os Portugueses a acceitaráo com bom grado, pois a Nação cada vez mais se vai illuminando, e procurando os bons Livros já nos seus mesmos Originaes, já nas Traducções que delles tão louvavel e utilmente se fazem." ${ }^{35}$ Sobre a tradução de José Amaro da Silva de $O$ Paraíso perdido, Rolland acreditava na boa aceitação da "lembrança, que tive com a Traducção deste Poeta" porque ele achava ser "justo que esta Nação tenha na sua Lingua tudo quanto nas outras houver, porque nem só os Sábios devem lêr, mas todos os outros, para que ou o sejão, ou se instruaõ."36

Portanto, segundo ele, seu esforço coincidia com a vontade geral de instrução segundo preceitos claros, e objetivos definidos. Sobre os Elogios históricos dos reis de portugal, ele escreveu:

Creio que terá toda a aceitação, lembrando-se o Público de que em nada mais cuido, do que em lhe fazer vulgares todos aquelles Livros em que se possão instruir, e desabusar. Pois da frequente lição he que os Homens podem adquirir conhecimentos proveitosos, emenda dos vicios, obediencia aos Soberanos e superiores; respeito á Religião, união e amor aos outros seus concidadãos,

34 MICENIO, op. cit.

35 RIGORD, op. cit.

36 MILTON, J. O paraíso perdido. Lisboa: Na typografia Rollandiana, 1789. [Trad. José Amaro da Silva]. 
mórmente da Historia, que he a Escóla do Mundo, a Mestra da vida, e a Testemunha dos tempos. ${ }^{37}$

Ele expressava assim a função que a leitura assumia, face aos discursos modernizantes típicos de seus contemporâneos portugueses devotados às "Luzes" um caráter redentor, ao qual ele associava a fruição pura e simples. Este foi o caso de $O$ viajante universal, de Laporte, cuja tradução (anônima) portuguesa Rolland publicou em 1798 com dois objetivos em mente: "a instrucção e o recreio". ${ }^{38} \mathrm{Em}$ suma, ele tinha certeza que suas "emprezas typographicas", ou seja, os "Livros antigos, e raros, que reimprimo, ou das Traducções dos melhores Authores Francezes, que vou publicando", seriam bemaceitas pelo público de língua portuguesa, principalmente porque ao longo de sua trajetória, cujo sucesso ele debita à "[n]ação: aos Sábios della, e até ao mesmo Povo", ${ }^{39}$ ele se tornou um bom conhecedor das demandas e necessidades da república das letras em Portugal.

Ao vermos os motivos que ele alegava em seus paratextos para ter empreendido tal ou qual edição, tradução ou reimpressão, nos damos conta desse conhecimento, expresso nas estratégias editoriais, associadas às motivações tradicionalmente ligadas à palavra impressa, como era a necessidade de preservar obras reconhecidas e em alta demanda pelos leitores. Na primeira edição das Obras poéticas de Domingos dos Reis Quita (quando ainda era sócio de José Agostinho Borel) ambos afirmavam, na dedicatória (provavelmente para o conde de Oeiras) que o que os motivou a imprimir a obra foi "[o] temor de que o tempo, que tudo estraga, perdesse, e consumisse para sempre as Obras Poeticas de Domingos dos Reis". "Uma década e meia mais tarde, quando ofereceu a público a segunda edição, Rolland disse que sua resolução devia-se ao fato da raridade da obra, e da vontade de "lhe dar nova vida, imortalizando mais o seu nome [...] e assim darei

37 BRITO, Fr. Bernardo. Elogios historicos dos reis de Portugal. Lisboa: Rollandiana, 1786. 38 LA PORTE. $O$ viajante universal ou noticia do mundo antigo e moderno. Tomo I. Lisboa: Na Typografia Rollandiana. 1798, p. vi.

39 ANDRADE, Jacinto Freire de. Vida de dom Joã̃ de Castro, quarto vice-rei da India. Lisboa: Na tipografia rollandiana, 1786.

40 MICENIO, op. cit. 
ao Público todas as Obras de hum Author nosso, e moderno". ${ }^{41} \mathrm{Na}$ mesma lógica, ele reimprimiu as Reflexões sobre a vaidade dos homens de Matias Aires Ramos, para "tiralla do escuro esquecimento em que jazia, e de quanta utilidade he para os homens [pois] Mal continuado, necessita continuado remedio." 42 Ele tinha, de fato, um grande projeto editorial: o de "dar á luz huma completa Collecção dos mais esclarecidos Poetas, de que se compoem o Parnasso Lusitano"43

No outro extremo da oferta editorial, clássicos grecoromanos eram necessários "em volume portatil por preço muito mais accommodado" pois em tais livros convinha "não haver coisa que perturbe a quem aprende, nem tambem se venderem por preços que desanimem a quem quizer valer-se delles". Foi este espírito que Rolland alegou para publicar a Arte Poética de Horácio em tradução portuguesa de Candido Lusitano. ${ }^{44}$ Além das qualidades intrínsecas de livros de autores estabelecidos, o uso prático que se podia fazer da obra também foi motivo para sua ação editorial:

[...] em huma palavra, para se conseguir huma razoavel intelligencia, e explicação das Fabulas, dos antigos Authores Gregos, e Romanos; para se suscitar o pensamento allegorico das Estatuas, dos Baixos-relevos, e outros muitos Monumentos, que se encontrão nos gabinetes dos Antiquarios, offereço ao publico a presente Traducção assaz admiravel, e interessante, porque o Author no Original intentou formar um resumo do conhecimento da Mythologia, por perguntas, e respostas, e muito abbreviado sem faltar ao necessario, nem amontoar o superfluo. $^{45}$

Junto às alegações de memória coletiva, Rolland enfatizava processos educacionais proporcionados por suas edições. No prefácio

\footnotetext{
41 Idem.

42 RAMOS, op. cit.

43 REAL, op. cit.

44 FLACCO, Horacio. Arte poetica ou epistola aos pisões. Lisboa: Na Officina Rollandiana, 1778. [Trad. de Candido Lusitano].

45 RIGORD, op. cit.
} 
das Regras da versificação portugueza, por hum anonimo, que publicou em 1777, ele reafirmava ter impresso o livro para auxiliar "os que principiaõ neste estudo" evitar as "monstruosidades, rusticidades, aspereza, e hum ar de proza, que quasi sempre se encontra na maior parte dos versejadores" que agrediam os olhos e ouvidos dos leitores/ouvintes. ${ }^{46}$ A oratória também era alvo de suas investidas comerciais, como foi o caso dos discursos traduzidos do francês "porque he justo que os Oradores, depois de lerem, e pensarem nos Oradores Originaes da sua própria Nação, vejam também os que nas outras mereceraõ credito, e estimaçaõ".

Ele atuou abrangendo todo o espectro da cultura escrita, desde o domínio da República das Letras, com obras clássicas, reimpressões e compilações, às escritas formais e escritas de cotidiano expressas em manuais e métodos de escrita. $\mathrm{Na}$ "advertencia do editor sobre a utilidade desta nova edição" de 1787, do Secretário portuguez de José Francisco Freire, Rolland explicitava suas motivações:

Conhecida he de todos a precisão de hum modelo para as cartas familiares, politicas, mercantís, e d'outros generos: e por isso, sem olhar as despesas, e empates de lucros, me resolvi reimprimir o Secretario Portuguez, Obra que tem tido grandes applausos, e boa acceitação, naõ só porque até agora naõ sahio á lus outra neste genero, mas tambem pelo nome de seu respeitavel Author, bem conhecido entre os Literatos, por seus escritos, que tanto hornarõ a nossa Naçaõ, como a doutissima, e Religiosa Sociedade, de que foi membro, e a que tanto lustre deo com seus avultados talentos, e consummado desabuso. ${ }^{48}$

\footnotetext{
47 ANÔNIMO. Panegyricos e Discursos Evangelicos recompilados e traduzidos dos melhores Oradores Francezes e Italianos. Lisboa : Typ. Rollandiana, 1784.

48 FREIRE, Jozé Francisco. Secretario Portuguez ou Methodo de escrever cartas. Lisboa: Na Typografia Rollandiana, 1787.
}

46 ANÔNIMO. Regras da versificação portugueza. Lisboa: na Typographia Rollandiana, 1777. 
Embora as ciências em geral não tivessem sido enfatizadas por Rolland em sua ação editorial (mesmo nas traduções), a honrosa exceção foi a medicina, em especial com o lançamento dos dez volumes da Medicina Doméstica de Guilherme Buchan, publicados entre 1788 e 1803. Ao prefaciar o primeiro volume da obra, influenciado pelo sucesso da obra original, afirmou que "não podendo concorrer, como desejára, para a saude dos Póvos, ao menos me canso por mostrar que tenho este ardente desejo, para resolver-me a acceitar, e dar ao prélo esta Traducção."49 Este empreendimento foi sucedido pela publicação de um Vade Mecum, em 1804, "approvado já por hum celebre Pratico" uma vez que "[a] concisaõ, com que o Author anonymo tratou as principaes maximas da Medicina Pratica, o faz digno de recommendar-se aos que ocupados em cuidar de hum grande numero de doentes, naõ tem vagar para buscallas em Obras volumosas" $\$ 0$

Outra questão a ser vista é a ênfase dada na "utilidade" das obras publicadas. Um estudo sobre os paratextos dos tradutores portugueses no período revelou ser este um tema recorrente e que assumia, com frequência, a noção de que as traduções (e, por extensão, os livros em geral) eram instrumentais no processo de "instrução", que, à época, relacionava-se "ao cultivo de habilidades e conhecimentos bem plantados na preparação mais sólida realizada pela educação moral e voltada para o desenvolvimento da civilidade". ${ }^{31}$ Foi no sentido de instruir os portugueses menos afeitos às lides intelectuais, ou menos familiarizados com outros idiomas (outro topos recorrente), que o vice-reitor do Colégio dos Nobres, José Dias Pereira, apresentou sua Traducção da defeza de Cecilia Faragó, em 1775:

49 BUCHAN, op. cit

50 ANÔNIMO. O Vade Mecum do medico ou breve resumo de medicina pratica. Extrahido das Obras dos mais celebres Medicos; Traduzido do Inglez em Francez e deste em Portuguez. Lisboa: Na Typografia Rollandiana. 1804.

51 DENIPOTI, Cláudio \& FONSECA, Thais Nivea de Lima e. Censura e mercê - os pedidos de leitura e posse de livros proibidos em Portugal no século XVIII. Revista Brasileira de História da Ciência, Rio de Janeiro, v. 4, n. 2, p. 139-154, jul | dez 2011, p. 150. 
Recebe o homem apenas começa a ouvir, e entender, grandes, e infinitas preoccupações. As Amas, ordinariamente grosseiras e supersticiosas ora entretem as crianças com a medonha narração dos Lobishomens, e das Fantasmas, que appareceram nos escuros lugares (com se receasse o demonio até a luz de huma vela) ora com os extraordinarios e maravilhosos casos dos Magicos, e das Feiticeiras. Livram-se desses nocivos erros os Sabios, examinando, e pezando com criterio as opiniões dos seus primeiros annos. Destes abusos pertendemos salvar os nossos Compatriotas, (que forem menos instruidos, e ainda os conservarem) pelo meio da presente Traducção. $^{52}$

O mesmo tradutor, envolvido com o processo mais amplo, iniciado pelo Marquês de Pombal, de combate às ideias jesuíticas, em um segundo trabalho sobre o tema da feitiçaria - a Arte mágica aniquilada, de Scipione Maffei, publicada em 1783 -, reiterou a ideia da utilidade da tradução em promover a instrução, na medida que pretendia empreender "somente a instrucção daquellas pessoas, que a penas lem, e entendem a nossa língua vulgar", uma vez que ele considerava haver, entre os "Portugueses eruditos" um conhecimento suficiente da língua italiana para dispensar a leitura da tradução. ${ }^{53}$

O "ser util" passava também por processos educativos da língua portuguesa, uma vez que as traduções poderiam ensinar sobre uma certa ortodoxia gramatical, além de ajudar a desenvolver estilos. João Rosado de Villalobos e Vasconcelos, em sua tradução de $O s$ costumes dos israelitas,${ }^{54}$ afirmou ter traduzido para que os leitores portugueses tivessem "importantes liçoens sobre a pureza da fraze, castidade da dicção, \& simplicidade de estilo, mui differente da affectação de alguns puritanos". Foi neste mesmo sentido que a

52 PEREIRA, José Dias. Traducção da defeza de Cecilia Faragó, accusada do crime de feitiçaria : ... Lisboa: Off. Manuel Coelho Amado, 1775.

53 DENIPOTI, Cláudio; PEREIRA, Magnus Roberto de Mello. Feitiçaria e iluminismo: traduções e estratégias editoriais em Portugal no Século XVIII. Revista Maracanan, v. 10, n. 10, p. 48-63, 2014

54 FLEURY. Os costumes dos israelitas. Lisboa: Na Tipografia Rollandiana, 1778. [Trad. João Rozado de Villalobos e Vasconcellos.] 
tradução que João Guilherme Christiano Muller, secretário da Academia de Ciências de Lisboa, fez da Memoria sobre a literatura portugueza de Robert Southey teve por objetivo mostrar aos seus leitores lusitanos o quanto sua literatura era conhecida fora das terras do Império:

Se publicamos pois a traducção deste Ensaio não hé por que estejamos em todos os pontos de accordo com o seu Author, nem taõ pouco porque o julguemos completo; senão para fornecer aos Portuguezes eruditos occasião de saberem o conceito que novissimamente se forma em outros Payses cultos, do merecimento literario desta Nação, e para [1]hes dar igualmente azo de accressentarem, e corrigirem os juizos de hum Estrangeiro, que achou nossas producções litterarias dignas de seu assiduo estudo e applicação. ${ }^{55}$

Este era outro aspecto da ideia de utilidade presente nas justificativas dos tradutores: a maneira como Portugal poderia ser visto, ou interpretado, por si próprio e pelas demais potências europeias, em uma época de enormes agitações políticas e diplomáticas. Custodio José de Oliveira em sua tradução de Sobre o modo de escrever a história de Luciano, afirmou esperar que sua tradução servisse para que os "feitos clarissimos, e dignos de immortal memoria" da Nação Portuguesa sejam eternizados em "monumentos dignos das suas illustres acções". 56

Uma última série discursiva relativa à ideia de utilidade verificada nestas fontes refere-se às obras mais fortemente identificadas com a imagem "utilitarista" criada sobre o Iluminismo lusitano, e diz respeito às traduções de obras científicas - ou de disciplinas que começaram a se firmar como tal na segunda parte do século XVIII. Também associadas à ideia de instrução discutida

55 SOUTHEY, Robert. Memoria sobre a literatura portugueza, traduzida do inglez; Com notas illustradoras por J.G.C.M. [Hamburg : s.n. 1809.][trad. João Guilherme Christiano Muller].

56 LUCIANO. Sobre o modo de escrever a história. Lisboa: Regia Officina Typografica, 1771. [Trad. Custodio José de Oliveira]. 
acima, estas justificações buscam inserir os textos traduzidos em contextos de "progresso" técnico e debate científico: Antonio Martins Vidigal, cirurgião da câmara real, por exemplo, apresentou sua tradução da Descripção das infermidades dos exercitos de VanSwiten, nestes termos:

As traducções dos bons livros forão em todos os tempos taõ favoralvemente admittidas na Republica das letras, quanto se julgavam estimaveis, e uteis. Igualmente, depois de averiguadas as suas grandes vantagens, se estabeleceo o seu distincto merecimento; e não era muito lhe conferirem a estimação, que he naturalmente inseparavel de tudo, o que instrue com suavidade e gosto. $^{57}$

Neste mesmo sentido, o tradutor anônimo do Tratado da pratica da Manobras dos Navio associou seus motivos ao "interesse público", uma vez que a obra deveria trazer "significante beneficio" a uma atividade necessária. ${ }^{58}$ Ainda, José Joaquim da Silva Peres traduziu o Guia de negociantes e de guarda-livros de La Porte em 1794 porque sentia "a sensível falta, que fazia a [lição] deste Livro, e a utilidade, que della resulta" para os negócios em geral. ${ }^{59}$

Assim, não devem "causar espécie" as alusões constantes de Francisco Rolland à utilidade dos livros que publicou, adotando diversas combinações destes significados. As Obras poéticas de Domingos dos Reis Quita pretendia tornar ainda mais conhecido um autor merecedor, que honrava a nação e cujas obras estavam "enterradas em hum vergonhoso silêncio", ${ }^{60}$ ao passo que a Noticia da mythologia "[m]erecia andar nas mãos de todos", porque Rolland

57 VAN-SWITEN. Descripção das infermidades dos exercitos. Lisboa: Typografia Rollandiana, 1786. 4a ed. [trad. Antonio Martins Vidigal].

58 FERNANDES, Antonio Gabriell. Tratado da pratica da Manobras dos Navios. 1789 [ANTT. Manuscritos da livraria n.89]

59 LA PORTE. Guia de negociantes e de guarda-livros. Lisboa: Regia Officina Typografica, 1794. [Trad. José Joaquim da Silva Perez].

60 MICENIO, op. cit. 
julgou que tratava-se de uma obra "tão util para o adiantamento, e perfeição de muitas artes uteis, e necessárias". ${ }^{61}$

Porém, na pena [e na prensa] de Francisco Rolland, a utilidade buscada dizia respeito aos projetos gestados em torno das ideias de ciência e arte como índices de civilização e poder nacional. Ao prefaciar o Naufragio e lastimoso sucesso da perdição de Manoel de Sousa de Sepulveda Rolland afirmava que seu objetivo, ao editar uma tal obra, era "cooperar, quanto em mim está, ao ennobrecimento de huma nação, que não he inferior as outras, que tanto se jactaõ de illustradas, em os conhecimentos das bellas Artes, e Sciencias" ${ }^{\circ 2}$ pois a "notícia dos seus escritores" tem utilidade clara para o "homem de juízo são, e puro":

por quanto nelles se bebem doutrinas solidas; fartam-se os Litteratos de antiguidades; estes aprendem os costumes dos passados tempos; estudão expressõens; enchem-se de conceitos sublimes, e delicados, e aproveitam-se da frase verdadeira; fazem senhores do idiotismo proprio, e particular da nossa linguagem; e assim se escusa mendigar das outras linguas as locuções, os modos genuinos de fallar, em que a nossa tanto abunda; mostrando-se que pela falta da lição dos Authores Portugueses. ${ }^{63}$

Seus esforços editoriais se relacionavam à utilidade que poderiam ter os livros editados, reimpressos ou traduzidos. No Caso dos Elogios historicos dos reis de Portugal, esta utilidade residia no fato do livro conter "em resumo quasi toda a nossa Historia Portuguesa" sem ser necessário recorrer aos muitos volumes de outros livros semelhantes. ${ }^{64}$ Ao passo que a leitura da Vida de dom Joaõ de

61 RIGORD, op. cit.

62 REAL, op. cit.

63 MIRANDA, Francisco de Sá de. Obras do doctor Francisco de Sá de Miranda. Lisboa: Na Typografia Rollandiana, 1784.

64 BRITO, op. cit. 
Castro podia "criar nos honrados peitos Portuguezes sentimentos briosos de imitar aos seus Maiores". ${ }^{65}$

Em geral, expressando o quão útil seus livros poderiam ser, Rolland demonstrava um conhecimento refinado das estruturas de poder que permitiam sua existência como livreiro, pois para que os livros atingissem o objetivo do editor de auxiliar a caminhada para a glória, dentro e fora do Império, as condições portuguesas eram propícias: "hum Ministerio Cuidadosissimo, hum Tribunal desabusado, e sabio, huma Soberana e Principes illuminadissimos, e desvelados pelo bem da Nação, hum Povo applicado." ${ }^{66}$ Ao editor, competia manter o discurso normativo que pregava o contínuo e crescente uso de "bons livros" para o bem comum, pois "[a]quelle Estado que he mais culto, e sabio, nelle são os Monarcas mais temidos, e obedecidos. Aonde ha despotismo, e ignorancia, ahi são todos os dias as sublevaçoens." ${ }^{67} \mathrm{E}$ ainda:

Hum Sabio Governo (como o nosso) deve ter summo cuidado em que ainda o mesmo povo lêia por livros em que os homens se pulem, não por aquelles que lhes embotem os sentidos, que lhes enchão a cabeça de immensas Superstições, de doutrinas subtis, corruptas, e extravagantes, nas quaes a verdade está mascarada, envolta em superfluidade, e ennovelada com tantas difficuldades e systemas que passao até fazer a nossa Religião pezada e insorportavel $[\ldots]^{68}$

No prefácio de sua tradução da Peregrinação de um christão Rolland reforçava essas ideias, com uma observação perspicaz sobre as mudanças sociais que ele mesmo pode ter presenciado, pois "[e]stamos no Seculo XVIII. As naçoes vão sacudindo os máos methodos, com que athé agora se vião opprimidas". Segundo ele a situação portuguesa era propícia à disseminação dos "bons livros" que

65 ANDRADE, op. cit.

66 VEIGA, op. cit.

67 FLACCO, op. cit.

68 RAMOS, op cit. 
editava por vários fatores. Em primeiro lugar, a "policia tem subido ao mais alto ponto de delicadeza", enquanto "[a] soberana, dotada de abalizados talentos, e desabuso ampara e protege as lettras, e o bom gosto, ama ao Publico, estima a policia, e quer que o seu Reino seja semelhante ao bom Seculo de Ouro". Para isso, a existência abundante de "eclesiásticos eruditos e desabuzados", uma Academia mantida por homens aplicados a executarem projetos em pról da "utilidade do Estado". 69

Se julgarmos somente por seus próprios paratextos editoriais, podemos ter uma ideia de como Rolland agia e se imaginava no tocante às sociabilidades letradas, atuando nos limites do seu papel de agente dos esforços ilustrados, tanto das diversas gerações de escritores portugueses, quanto como editor propriamente dito. Fica assim mais fácil compreender seus esforços textuais no jubilatio da estrutura censória e acadêmica. Porém, sua situação na estrutura social portuguesa fica distorcida por essas fontes. Como eram as suas relações com as estruturas de controle da atividade livreira (e com toda a estrutura de poder)?

Como todos os livreiros portugueses do período, Rolland tinha que lidar com o aparato censório em uma base cotidiana e nem sempre harmoniosa, fosse pedindo as licenças necessárias para imprimir um livro qualquer, fosse enviando os livros que vendia para as diversas partes do reino. Como, principalmente após a criação da Real Mesa Censória em 1768, qualquer transporte de livros necessitava ser autorizado, foram vários os seus pedidos para remeter livros para outras cidades do reino, ou para o Rio de Janeiro, como fez em 1796, acompanhando a solicitação da respectiva lista de livros enviados, para que os censores pudessem verificar não haver nada proibido ali. ${ }^{70}$ Noutro exemplo, cerca de duas décadas antes, ele obteve a mesma licença para enviar para América "um lote de livros, cujos títulos e quantidades se discriminavam em relação anexa ao requerimento. A licença concedida abrangia, entre outros, De l'esprit des lois de Montesquieu". ${ }^{71}$

69 BUNYAN, op. cit.

70 A.N.T.T. Real Mesa Censória, cx 153.

71 MARTINS, Maria Teresa Esteves Payan. A censura literária em Portugal nos séculos XVII e XVIII. Lisboa: Fundação Calouste Gulbenkian, 2005, p. 427; ANTT, RMC. Cx. 164. 
No tocante aos pedidos para comercializar livros em Portugal, já encontramos referências a sua ação junto às estruturas de censura em 1767, quando ele e seu sócio José Agostinho Borel negociaram a liberação da obra completa do Padre Croiset (traduções francesas de textos bíblicos) junto ao Tribunal do Santo Ofício. ${ }^{72}$ Porém, os embates entre Rolland e a Real Mesa Censória giraram em torno das obras proibidas, como foi o caso do Belisário de JeanFrançois Marmontel. Rolland publicara, clandestinamente, uma tradução portuguesa desta obra em 1778 e 1779 "seguindo a via clandestina", ${ }^{73}$ e pediu licença, em 1784, para "imprimir a tradução do Cap. 15 do Belisario de Marmontel, a diz estar reimprimindo." O censor, Antonio de Santa Marta Lobo, depois de analisar detalhadamente o conteúdo do capítulo em apreço, foi de parecer que "aquelle papel ficasse suprimido, e repreendido o tradutor por intentar fazer público um discurso que tinha proibição daquela Mesa, o que foi sancionado pelo Tribunal", ${ }^{74}$ marcando a "firmeza da Real Mesa Censória em não permitir a divulgação desta obra de Marmontel". ${ }^{75}$ Já a censura, feita em 1776, da tradução das Fábulas de Esopo feita por Manoel Mendes da Vidigueira opunha-se à tradução, uma vez que a obra já era suficientemente reputada na Europa, com ao menos uma edição portuguesa no século XVI. O censor, frei Mathias da Conceição, pediu que a licença de impressão não fosse dada sem que antes "se reforme a gramatica, a locução e ortografia delle", pois o estilo do tradutor pareceu, ao censor "insipido e fastidiozo pela falha de gramatica Portugueza, ou pela multidão de orações implexas, em que humas vezes falta o verbo, outras o Nominatio, que o Reja, outras finalmente vem estes no singular e aquelle no plural, ou vice versa". ${ }^{76}$ Aparentemente as ressalvas do censor foram resolvidas e a obra,

72 Idem, p. 185.

73 RODRIGUES, A. A. G. A tradução em Portugal. Lisboa: Imprensa Nacional-Casa da Moeda, 1992, vol. I. p. 164, n. 1256 e p. 167, n. 1295; MARMONTEL, Jean-François. Belizário. Lisboa: Typ. Rollandiana, 1779, [trad. Meneses, José de Nápoles Teles de]

74 ANTT. Real Mesa Censória, cx 13.

75 MARTINS, op. cit., p. 258.

76 ANTT. Real Mesa Censória, cx 9, 1776, n. 30. 
publicada com as devidas aprovações e licenças, com duas edições feitas por Rolland, em 1777 e $1791 .^{77}$

Não obstante, como regra, os censores liam os trabalhos enviados para análise, com olhares parecidos àquele de Rolland na redação de seus prefácios. Já no século XIX, o Tribunal do Santo Ofício aprovou a tradução do Viajante Universal de La Porte porque o censor não achou "coiza nenhuma contraria a Nossa Sta Fé, ou bons costumes, nem que se deva censurar". ${ }^{78}$ Duas décadas antes, a censura dos Adagios, Proverbios, Rifaos e Anexins, mencionados acima, demonstrava este encontro de interesses:

\author{
Senhora \\ Os Adagios, Proverbios, Rifaos e Anexins da Lingoa \\ Portugueza tirados dos melhores Authores Nacionaes q \\ Francisco Rolland pertende imprimir estão dispostos com \\ bom methodo seguindo exactamente a ordem alfabetica: \\ a sua lição não deixa de ter utilidade e nada contem q se \\ opponha aos bons costumes, ous as Leys do Estado e por \\ isso o Supplicante he digno da licença q pertende. Fôram \\ do mesmo parecer os Senhores Deputados Adjuntos. \\ Meza 2 de Março de 1780 \\ Fr. Franciso X,.er d Sta Anna e Fon. ca \\ Fr. Joaquim de Sta Anna \\ Fr. Luis de St.a Clara e Povoa ${ }^{79}$
}

Também como todos os outros livreiros portugueses, Rolland foi alvo da ação repressora da censura, que inspecionava estoques nas livrarias para coibir o comércio de livros defesos. Em especial, uma inspeção geral de seu estoque em julho de 1779. Atendendo a uma ordem real, inspecionaram o "Loge do Referido e na sua Oficina, e em dois Armazens" um Juiz de crime acompanhado de seu escrivão e dois "reverendissimos padres Mestres [...] procedendo no exame de todos os livros" guardados naqueles locais, sem encontrar nenhum

77 ESOPO. Fabulas de Esopo traduzidas da lingua grega com applicações moraes a cada fabula por Manuel Mendes Da Vidigueira. Lisboa: na Typografia Rollandiana, 1791.

78 ANTT. Tribunal do Santo Oficio, mç 57.

79 ANTT. Real Mesa Censória, cx 12, 1780, n. 9 
livro proibido, exceto dois jogos em espanhol da Historia do povo de Deos, que o próprio Francisco Rolland apressou-se a entregar aos inspetores. A reação de Rolland veio na forma de carta à Rainha, na qual ele não reclamava da inspeção em si, mas do excesso de rigor e do número de pessoas:

Representa a Vossa Magestade Francisco Rolland que no dia 9 do presente mês de julho, por ordem de Vossa Magestade lhe foi [assaltado?] a sua Casa com tal apparato de justiça, que com o maior aperto lhe tomaraõ portas, e devaçaraõ o mais interior das casas; Não fez isto soçobro no animo do Suppte, tranquillo na boa fe da sua innocente consciência, mas não puderaõ deixar de fazer effeito alvorotos em sua mulher pejada de muitos mezes, circunstancias em que taes apparatos costumam fazer maiores impressões. ${ }^{80}$

A seguir ele explicava a origem dos livros que entregou aos inspetores, que haviam sido remetidos de Coimbra por Pedro Borel em 1774, e que já haviam sido submetidos à Real Mesa no momento da retirada das obras na alfândega. Ainda que a provisão estivesse vencida, ele afirmou ter esquecido de pedir sua renovação, primeiramente porque ele afirmava não estar mais no negócio de "livros vindos do estrangeiro", e "maiormente quando o [suplicante] fazia tão pouca conta com os ditos jogos de livros, que se depositamente lhe Mal fallassem nelles, não devia ter os onde os tinha pois estavaõ de mistura com livros velhos a que bem se pode dar o titulo de Alfarrabios". ${ }^{81}$

Ao menos em uma situação Rolland diferenciou-se dos demais livreiros, quando viu-se roubado dos livros apreendidos pela Real Mesa Censória. ${ }^{82}$ Em 1777, ele denunciou o secretário da Real Mesa, Alexandre Ferreira de Faria Manoel, por se recusar a entregar

80 ANTT. Real Mesa Censória, caixa 177.

81 ANTT. Real Mesa Censória, caixa 177.

82 MAXWELL, Kenneth. Pombal. Paradox of the Enlightenment. Cambridge: Cambridge University Press, 1995, p. 108. 
um conjunto de livros apreendidos e que Rolland obtivera licença para devolver ao vendedor original, "somente por elle [o secretário] querer servir-se d'elles, como se prova que procurando-se na dita meza por elles, lá não existem" ${ }^{83}$ Segundo Rolland, a "cavilação" do secretário necessitava ser sanada para livrar o tribunal das "manchas e nódoas" que só começaram a existir com ele. A denúncia foi reforçada por outra semelhante, de Francisco Luiz Ameno, outro impressor lisboeta particularmente ativo no período. Ameno informava à Rainha que exemplares de uma obra (Horas da semana santa) que ele imprimira em 1762, e fora recolhida alguns anos mais tarde pela censura, estavam sendo vendidos "já por alguns livreiros, e já por Negociantes volantes, como a elle [suplicante] constou sendo ainda por encadernar", pelo que ele solicitava saber se a proibição fora levantada, e pedia indenização "como a [justiça] ordena com similhante cazo". ${ }^{84}$

As diversas investigações feitas pelos juízes de Lisboa chegaram à conclusão que Faria Manoel se apropriava dos livros retidos pela Real Mesa Censória e os repassava a Vicente Pedro de Lacerda, livreiro na cidade do Porto, e seu sócio Francisco José Fernandes. Estes revendiam os livros na cidade do Porto e na feira de Viseu, com a participação de um terceiro livreiro, Francisco Clamorin Durand. Na prisão e investigação sobre Lacerda, o interrogatório do juiz resumiu o processo de roubo e receptação dos livros:

Interrogatórios:

Donde, como e por que meios houve as Horas do Officio de Nossa Senhora em Portugues, impressas a custa de Luis de Moraes e vendidas por elle Vicente Pedro de Lacerda a seu compadre Francisco Clamopin Durand, e a outras pessoas, na cidade do Porto e na feira de Vizeu, desde o anno de 1775 ?

Porque preço vendeo as ditas Horas e quantos foram os exemplares que teve dellas?

Donde, como e porque meios houve a avultada porção de Livros antigos, e pertencentes as livrarias que forão dos

83 ANTT. Real Mesa Censória, caixa 177. 84 ANTT. Real Mesa Censória, caixa 177. 
extintos jesuitas, que vendeo per si, e por seus correspondentes nas cidades de Coimbra, Vizeu e Porto? Quantos foram os caixotes dos ditos Livros que desta corte lhe forão remettidos a Coimbra pela [???] e a que tempo ${ }^{85}$

Rolland participou ativamente do processo, denunciando ou desmentindo os envolvidos, cuja punição foi a prisão e a proibição de voltar a comercializar livros. Tempos depois da denúncia original, ele apressou-se em desmentir o livreiro Lacerda, que afirmou em juízo ter cartas do secretário da Real Mesa Censória "nas quaes se dizia que podia comprar as partidas de livros que lhe remetia, porque o Estrangeiro Rolland/ que he o supp.te/ havia já comprado outras maiores porções." Segundo Rolland, a afirmação era "falcíssima" e criada somente para convencer o livreiro a fazer a compra, e que o secretário queria "fazer laço àquele comprador". ${ }^{86}$

Não sabemos se Rolland ou Francisco Ameno receberam seus livros ou algum valor indenizatório sobre eles, como queriam. Dos diversos livros que Rolland citou no rol que acompanhava sua denúncia original e que chegavam, segundo ele, a um total de $103 \$ 400$, ele somente afirmou ter recebido $19 \$ 200$ diretamente de dom Manoel do Cenáculo, o Bispo de Beja, presidente da Real Mesa Censória, que "se obrigou a me pagar" por cinco volumes da obra de Bocage (que ficamos sem saber se é o poeta português, ou a obra em cinco volumes de Madame du Bocage, impressa em Lion em 1770).

O que toda esta documentação evidencia sobre a atuação de Rolland no universo letrado português da segunda metade do século XVIII e início do século XIX?

Em primeiro lugar, que ele estava integrado a uma determinada racionalidade do escrito presente no circuito de comunicação do livro, que priorizava simultaneamente o convencimento dos leitores sobre as obras publicadas, a erudição dos autores e tradutores e a superação das barreiras impostas pelos mecanismos de censura e polícia do Estado, ainda que agindo, na 
maior parte do tempo, dentro dessas barreiras. Este três pontos permitem uma melhor compreensão das recorrências discursivas de seus paratextos, em particular sobre as expectativas de recepção das obras publicadas e a descrição laudativa do aparato estatal.

Em segundo lugar, estas recorrências encontram eco em diversos outros escritos - de autores, tradutores, censores e leitores que enfatizaram pontos comuns com relação às ideias em torno do livro e da leitura. A visão do texto impresso como parte essencial da constituição de identidades "nacionais" - especialmente em torno da ideia de utilidade que acompanha o esforço editorial de Rolland e de outros impressores e autores - é parte constituinte do Iluminismo lusitano. O livro como processo de redenção é, de fato, uma constante em textos, paratextos editoriais e manuscritos relacionados ao mundo do livro, e sua circulação por diversas partes do império garantia que os súditos portugueses que pertenciam ou ansiavam pertencer às redes de patronato ligadas à República das Letras, incorporassem gradativamente este valor.

Em sua historicidade, o mundo do livro e seus processos de sociabilidade letrada têm na Tipographia Rollandiana uma expressão do tipo de discurso predominante e do tipo de uso e prática da palavra escrita que marcou a segunda metade do século XVIII no Império Português. Ele era parte integral da República das Letras, sobre a qual era simultaneamente necessário lançar um olhar vigilante e amparar para que florescesse.

RECEBIDO EM: 06/06/2016 APROVADO EM: 01/05/2017 